NSL 07843

\title{
Protease nexin-1 activity in cultured Schwann cells
}

\author{
L.P. Mulligan ${ }^{1}$, D.E. Rosenblatt ${ }^{2}$, R. Toms ${ }^{1}$ and D. Johnson ${ }^{1}$ \\ ${ }^{1}$ Center for Neurologic Disease, Brigham and Women's Hospital, Boston, MA 02215 (U.S.A.) and ${ }^{2}$ Department of Internal Medicine, University of \\ Michigan, Ann Arbor, MI 48109 (U.S.A.)
}

(Received 26 November 1990; Revised version received 29 March 1991; Accepted 30 March 1991)

Key words: Schwann cell; Tissue culture; Nexin; Protease inhibition; Immunochemistry

\begin{abstract}
We report that protease nexin-1 (PN-1), a serine protease inhibitor known to have neurite-promoting effects, is made by Schwann cells in tissue culture. Three modalities have been used to demonstrate the presence of PN-1 in Schwann cell cultures. Immunostaining of the cultures with anti-PN-1 antibody gives positive staining over cells and matrix. Western blots of Schwann cell conditioned medium (CM) using anti-PN-I antibody show a band that co-migrates with the PN-1 standard at $45 \mathrm{kDa}$. Biochemical assay for protease inhibitory activity shows that $\mathrm{CM}$ inhibits thrombin activity in a calorimetric assay. The CM-mediated inhibition of thrombin is reversed if the CM is pre-incubated with anti-PN-1 antibody.
\end{abstract}

It has been hypothesized that the balance between proteolytic and protease inhibitory activity plays an important role in normal neuronal development and in the response of the nervous system to injury [16]. The protease nexins are a group of serine protease inhibitors that were originally described in conditioned media from forskolin fibroblast cultures. They are classified by molecular weight and by the pattern of proteases they inhibit [10]. Protease nexin-1 (PN-1) is the best characterized of the nexins, and has been demonstrated in conditioned media from a variety of cell types [1], including astroglia [18]. PN-1 has been shown to be identical to the glialderived neurite promoting factor (now re-named gliaderived nexin) that affects neuronal migration and neurite extension [5, 11]. Changes in PN-1 activity have been demonstrated in the normal developmental processes of the central nervous system (CNS) [21] and in the pathological processes associated with Alzheimer's disease [19]. In the peripheral nervous system, sciatic nerve injury has been shown to result in increases in PN-1 message RNA [15]. Although tissue culture studies suggest that astrocytes are potentially major producers of $\mathrm{PN}-1$ in the CNS, the cell type responsible for PN-1 production in the peripheral nervous system (PNS) has not previously been clearly identified. Schwann cells share many properties with astrocytes and are candidates for this role. The present report describes the immunocytochemical, biochemical and functional demonstration of PN-1 in cultured Schwann cells.

Correspondence: D.E. Rosenblatt, University of Michigan, Institute of Gerontology, 300 N. Ingalls, Ann Arbor, MI 48109-2007, U.S.A.
Sciatic nerve Schwann cells were prepared and purified according to the method described by Brockes et al. [3]. Briefly, sciatic nerves were dissected from neonatal Sprague-Dawley rats (Charles River, Wilmington, MA), dissociated with $0.1 \%$ collagenase and $0.25 \%$ trypsin in L-5 medium and plated overnight on poly-L-lysine in Dulbecco's modified Eagle's medium (DMEM) containing $10 \%$ fetal calf serum (Gibco, Grand Island, NY) and $10^{-5} \mathrm{M}$ cytosine arabinoside. After $48-72 \mathrm{~h}$, the cells were trypsinized and suspended in mouse anti-Thy 1.1 (TIB 103, American Type Culture Collection, Rockville, MD) followed by rabbit complement (Pel-Freeze, Rogers, AR) to lyse the fibroblasts. Following this, Schwann cells were plated in $35 \mathrm{~mm}$ tissue culture plates coated with poly-L-lysine and grown in medium containing $2 \times 10^{-6}$ forskolin and bovine pituitary extract as described by Porter et al. [17]. After one week in culture, immunostaining was done with anti-Thy 1.1 and fluorescein-conjugated goat anti-mouse immunoglobulin (Sigma, St. Louis, MO) to confirm removal of fibroblasts. If positive cells were observed, the complement lysis was repeated. Cells were passaged once they reached confluence and after about three months in culture, they began to show signs of becoming autocrine, as described by Porter et al. [17] for Schwann cells grown under similar conditions. As in that previous study, cells that became mitogen-independent displayed a range of morphologies from broad and flat to typical early passage Schwann cells. The cultures remained Thy 1.1 negative throughout these experiments. To prepare conditioned media the cultures were placed in serum-free medium containing $1 \mathrm{mg} / \mathrm{ml} \mathrm{BSA}$ for $48 \mathrm{~h}$. This was 
done to prevent complex formation between $\mathrm{PN}-1$ and proteases in the FCS. After removal from the cells the medium was concentrated 5-fold using Centricon filters (Amicon, Danvers, MA) and assayed for thrombin inhibitory activity in a Chromozym-TH (Boehringer Mannheim, Indianapolis, IN) calorimetric assay [2]. Preincubation of the conditioned medium with anti-PN-1 antibody was used to test whether the thrombin inhibition was due to PN-1. A polyclonal rabbit anti-PN-1 antibody [19] was used in all experiments. For the immunohistochemistry and the Western blotting, a protein A fraction was prepared from the anti-PN I serum using an Affi-Gel Protein A MAPS kit (Biorad, Riverside, CA). PN-1 was purified from $\mathrm{C} 6$ glioma conditioned medium by the method of Scott et al. [22] and conjugated to $\mathrm{CN}$ Br Sepharose 4B (Pharmacia, Piscataway, NJ) according to the manufacturer's instructions. The PN-1-Sepharose was then used to affinity-purify the protein A fraction. The protein $A$ fraction remaining after removal of the
Sepharose beads was used as an anti-PN-1 antibodydepleted control. Affinity purified anti-PN-1 reacted positively with purified PN-1 in a Western blot system, while the anti-PN-1 depleted control was negative.

To test for PN-1 activity in Schwann cell conditioned medium, the cells were cultured in serum-free medium without growth factors for $24-48 \mathrm{~h}$. The medium was then harvested and concentrated ten-fold in a Centricon system (Amicon). The concentrated medium was then electrophoresed on a $10 \%$ polyacrylamide gel [14] and electroblotted onto nitrocellulose [23]. The nitrocellulose was then cut into strips which were immunostained with the rabbit anti-PN I (or with the anti-PN-1-depleted antiserum) and developed by incubation with alkaline phosphatase conjugated anti-rabbit IgG (Promega, Madison, WI). Immuno-cytochemical testing of the cultures for PN-1 activity was done by standard procedures [4] on cells seeded at $1-2 \times 10^{-5} /$ well on poly-L-lysinecoated glass cover slips in 12 well plates.
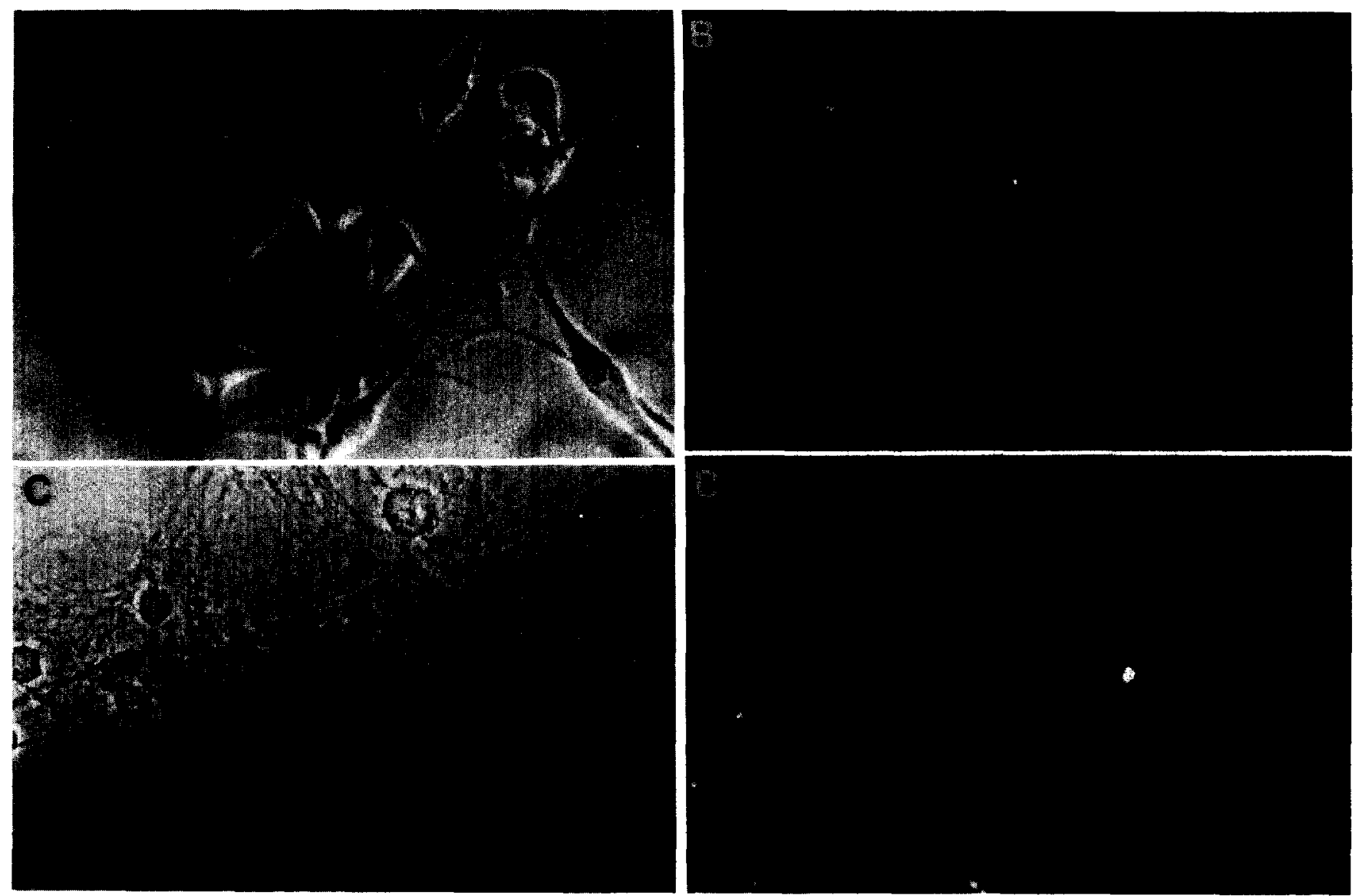

Fig. 1. PN-1 immunofluorescent staining in Schwann cell cultures. A: phase contrast microscopy of primary Schwann cells. $\times 400$. B: rhodamine fluorescence microscopy of the same field as A. Cells were grown and immunostained with anti-PN-1 antibody as described in the text. Punctate staining of Schwann cell membranes can be seen. C: phase contrast microscopy of autocrine Schwann cells. $\times 400$. Note the flattened morphology. D: rhodamine fluorescence microscopy of the same field immunostained with anti-PN-1 antibody and fluorescent second antibody. Note dense positive staining on extracellular matrix. Neither normal rabbit serum nor anti-PN-1 antibody-depleted serum produced any staining in any of these cultures. 
In initial studies, Schwann cell cultures were immunostained with the anti-PN-1 antibody and a rhodamine-conjugated second antibody to assay for the presence of PN-1. Primary cells showed a typical Schwann cell morphology under phase microscopy (Fig. 1A) and expressed faint traces of positive staining for PN-1 in either the presence or absence of growth factors (Fig. 1B). In contrast, autocrine Schwann cells showed a flattened morphology (Fig. 1C) and appeared to produce considerable quantities of PN-1 [10]. The pattern was suggestive of extracellular matrix staining and appeared strongest in those parts of the dish not occupied by Schwann cells. Some punctate staining of cell membranes was also observed. A similar pattern was seen with affinity purified anti-PN-1. There was no staining above background in either the primary or the autocrine Schwann cells when the PN-1 antibody-depleted prepa-

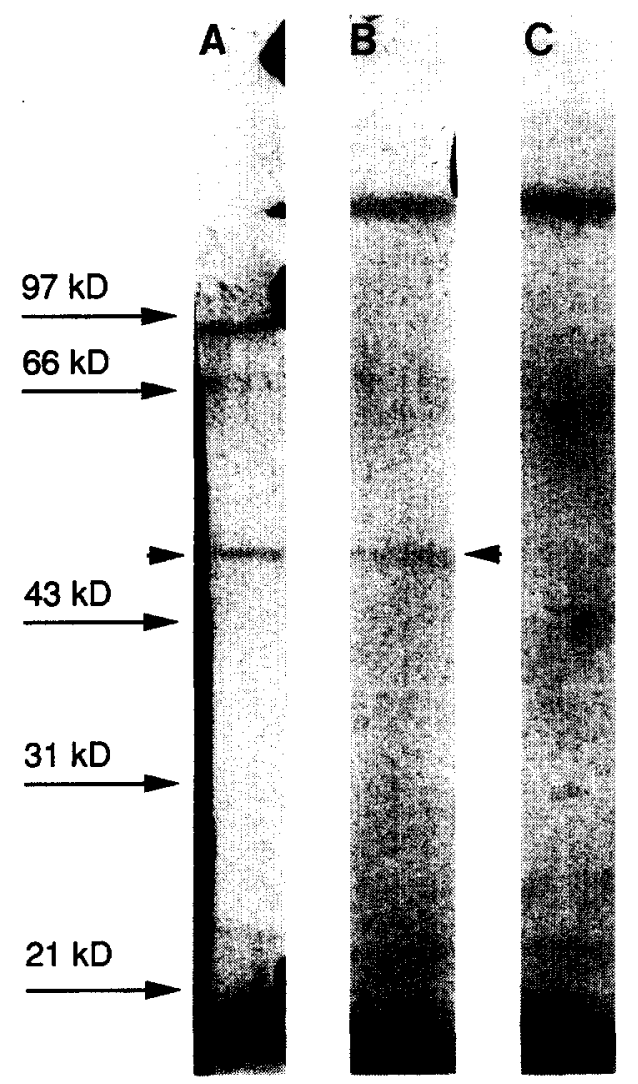

Fig. 2. Western blot of Schwann cell conditioned media. Conditioned media from autocrine Schwann cells was concentrated 10-fold and resolved on a $10 \%$ SDS-polyacrylamide gel. The gel was electrophoretically blotted onto nitrocellulose paper and stained. A: purified PN-1 standard; staining with anti-PN-1 antibody demonstrates the typical PN-1 band at $43 \mathrm{kDa}$ and a PN-1 dimer at $92 \mathrm{kDa}$. B: conditioned medium; staining with the anti-PN-1 antibody shows a band (arrow) that co-migrates with the $\mathrm{PN}-1$ standard at $43 \mathrm{kDa}$. C: conditioned medium; staining with anti-PN-1 antibody-depleted antiserum shows loss of the band at $43 \mathrm{kDa}$ suggesting that the Western blot is demonstrating $\mathrm{PN}-\mathrm{I}$ in the conditioned medium. ration was used. Although the autocrine cells are not dependent on exogenous growth factors for proliferation in vitro, some autocrine cells were also cultured with growth factors. This treatment led to a clear reduction of PN-1 immunostaining when compared to cultures maintained without growth factors.

Based on the results from the immunocytochemical studies, autocrine cells grown in the absence of growth factors were selected as the best source of the immunoreactive PN-1-like material and were therefore used to condition medium for biochemical and functional assays for PN-1. Conditioned medium was electrophoresed on SDS-PAGE, electroblotted to nitrocellulose and immunostained with anti-PN-1 antibody (Fig. 2). The immunostaining revealed a protein from the conditioned medium that migrated close to the position of the purified PN-1 standard. Immunostaining with control antibody preparations was negative.

To assay for the presence of PN-1-like protease inhibitory activity the conditioned medium was tested in a Chromozym-TH assay. Pre-incubation of thrombin with the conditioned medium led to a $23 \%$ inhibition of thrombin activity in the assay as shown in the graph from a typical experiment (Fig. 3). This inhibition was prevented by preincubation of the conditioned medium with anti-PN-1 antibody.

This report presents immunohistochemical, biochemi-

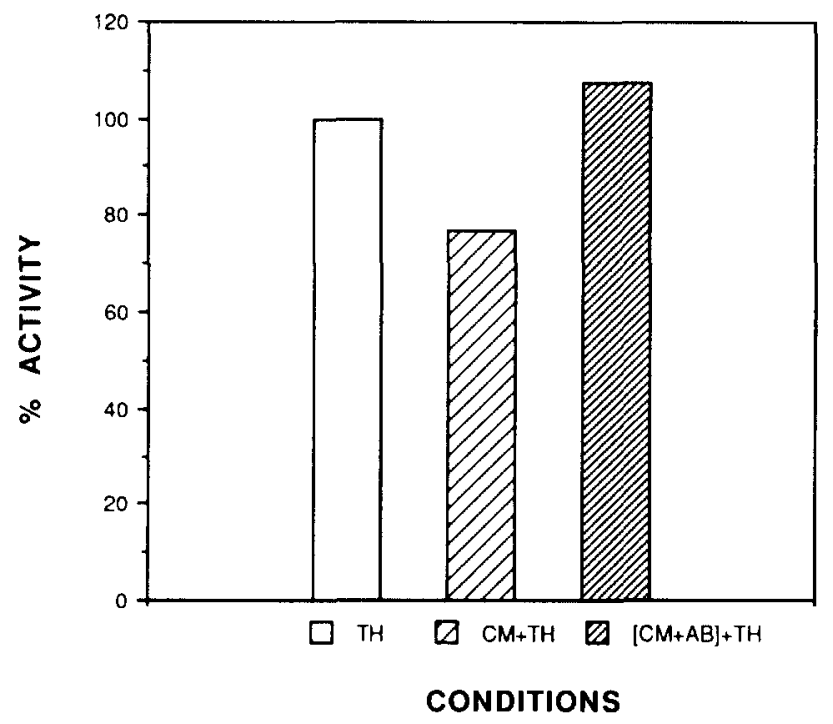

Fig. 3. Antibody inhibition of protease inhibitory activity in Schwann cell conditioned medium. Conditioned medium (CM) was harvested from autocrine Schwann cells grown in transparent media for $48 \mathrm{~h}$. It was concentrated approximately 5 -fold and introduced into a thrombin-Chromozym-TH assay in which it demonstrated thrombin inhibitory activity. In order to determine whether this activity was due to $\mathrm{PN}-1$, a sample of $\mathrm{CM}$ was pre-incubated with anti-PN-1 antiserum before incubation with thrombin and Chromozym-TH. The anti-PN-1 antiserum inhibited the protease inhibitory activity in the $\mathrm{CM}$ as was demonstrated by a complete reversal of the thrombin inhibition. 
cal and functional data that support the premise that cultured autocrine Schwann cells produce $\mathrm{PN}-1$ or a very closely related molecule. Schwann cell cultures had positive immunostaining for PN-1. Western blots of conditioned medium showed a band that co-migrated with a PN-1 standard. A functional assay for thrombin inhibition showed inhibition that could itself be inhibited by anti-PN-1 antibody.

PN-1 is the best studied of the nexin family of serine protease inhibitors and has been shown to be identical to the glial-derived neurite promoting factor [5, 11]. Although PN-1 production has been demonstrated in astrocytes [18], it has not previously been reported in Schwann cells. Schwann cells interact with neurons both during normal development and in response to nerve injury. Presumably, neuron-glia signalling modulates both glial mitogenesis and glial production of neurite promoting/trophic factors. Although Howard has reported that in fibroblast cultures $\mathrm{PN}-1$ secretion is constitutive [8], PN-1 secretion has not been fully characterized either in astrocytes or in Schwann cells. Growth in culture, in the absence of neurons (or the target cells for fibroblast PN I), probably represents an abnormal system lacking in controls and resulting in constitutive production. It is of note that $\mathrm{PN}-1$ production in the Schwann cells appeared to be greatest in the autocrine cells. Porter et al. have described these cells as retaining cell surface markers and the ability to ensheathe axons, but also having the ability to proliferate in the absence of growth factors or mitogens [17]. It has been suggested that they have lost the ability to regulate their own response to the autocrine factor that they secrete. These cells also make more autocrine factor than do primary Schwann cells. The high levels of PN-1 production in these cells may be analogous to their high levels of autocrine factor production. The suppression of autocrine cell production of PN-1 by addition of growth factors may represent restoration of a modulating signal.

In fibroblast culture PN-1 is secreted and much of it becomes bound to the extracellular matrix [4]. Schwann cells also produce extracellular matrix and the staining pattern seen in the Schwann cell cultures suggests that a similar process is going on in these cultures. It is reported that matrix binding in fibroblast cultures changes the affinity of $\mathrm{PN}-1$ for substrate proteases [25].

Although the exact mechanism(s) through which PN-1 exerts its effects on neurons has yet to be definitively demonstrated, it is of note that the enzymes inhibited by PN-1 are important in neuronal migration [24], neurite extension [6, 13], nerve muscle synapse formation and response to injury [7], neuron ensheathment by Schwann cells [9] and modification of the neurotrophic factor $\beta$ nerve growth factor $[12,20]$. As Schwann cells are involved in many of these processes, it is perhaps not surprising to find that Schwann cells make PN-1. There is a growing body of knowledge on neuronal and glial proteolytic activity in both the central and peripheral nervous systems [26]. It has been suggested that a crucial balance between proteolytic and protease inhibitory activity is a sine qua non for both normal neuronal development and for neuronal response to injury. Further studies are needed to elucidate the role of Schwann cell $\mathrm{PN}-1$ both in normal development and in the response to nerve injury.

1 Baker, J.B. and Gronke, R.S., Protease nexins and cell regulation, Sem. Thromb. Hemostasis, 12 (1986) 216-220.

2 Bartl, K. and Lill, H., A versatile assay method of antithrombin III using thrombin and TOS-GLY-PRO-ARG-pNA, Thromb. Res., 18 (1980) 267-272.

3 Brockes, J.P., Fields, K.P. and Raff, M.C., Studies on cultured rat Schwann cells. I. Establishment of purified preparations from cultures of peripheral nerve, Brain Res., 165 (1979) 105-108.

4 Farrell, D.H., Wagner, S.L., Yuan, R.H. and Cunningham, D.D., Localization of protease nexin-1 on the fibroblast extracellular matrix, J. Cell. Physiol., 134 (1988) 179-188.

5 Gloor, S., Odink, K., Guenther, J., Nick, H. and Monard, D., A glia-derived neurite promoting factor with protease inhibitory activity belongs to the protease nexins, Cell, 47 (1986) 687-693.

6 Gurwitz, D. and Cunningham, D.D., Thrombin modulates and reverses neuroblastoma neurite outgrowth, Proc. Natl. Acad. Sci. U.S.A., 85 (1988) 3440-3444.

7 Hantai, D., Rao, J.S. and Festoff, B.W., Serine proteases and serpins: their possible roles in the motor system, Rev. Neurol., 144 (1988) 680-687.

8 Howard, E.W. and Knauer, D.J., Biosynthesis of Protease nexin-I, J. Biol. Chem., 261 (1986) 14184-14190.

9 Kalderon, N., Migration of Schwann cells and wrapping of neurites in vitro: a function of protease activity (plasmin) in the growth medium, Proc. Natl. Acad. Sci. U.S.A., 76 (1979) 5992-5996.

10 Knauer, D.J. and Cunningham, D.D., Protease nexins: cell secreted proteins which regulate extracellular serine proteases, Trends Biol. Sci., May (1984) 231-233.

11 Knauer, D.J., Orlando, R.A. and Rosenblatt, D., The glioma cellderived neurite promoting activity protein is functionally and immunologically related to human protease nexin-1, J. Cell. Physiol., 132 (1987) 318-324.

12 Knauer, D.J., Scaparro, K.S. and Cunningham, D.D., The subunit of $7 \mathrm{~S}$ nerve growth factor binds to cells via complexes formed with two cell-secreted nexin, J. Biol. Chem., 257 (1982) 15098-15104.

13 Krystosek, A. and Seeds, N.W., Plasminogen activator release at the neuronal growth cone, Science, 213 (1981) 1532-1534.

14 Laemmli, U.K., Cleavage of structural proteins during the assembly of the head of bacteriophage T4, Nature, 227 (1970) 680-685.

15 Meier, R., Speyer, P., Ortmann, R., Harell, A. and Monard, D., Induction of a glia-derived nexin after lesion of a peripheral nerve, Nature, 342 (1989) 548-550.

16 Monard, D., Cell-derived proteases and protease inhibitors as regulators of neurite outgrowth, Trends Neurosci., 11 (1988) 541 544.

17 Porter, S., Clark, M.B., Glaser, L. and Bunge, R.P., Schwann cells stimulated to proliferate in the absence of neurons retain full functional capacity, J. Neurosci., 6 (1986) 3070-3080. 
18 Rosenblatt, D.E., Cotman, C.W., Nieto-Sampedro, M., Rowe, J.W. and Knauer, D.J., Identification of a protease inhibitor produced by astrocytes that is structurally and functionally homologous to human protease nexin-1, Brain Res., 415 (1987) 40-48.

19 Rosenblatt, D.E., Geula, C. and Mesulam, M.-M., Protease nexin I immunostaining in Alzheimer's disease, Ann. Neurol., 26 (1989) 628-634.

20 Rosenblatt, D.E., Woo, J. and Mobley, W.C., Protease nexin-1 is a substrate for $\beta$-nerve growth factor endopeptidase, submitted.

21 Schurch-Rathgeb, Y. and Monard, D., Brain development influences the appearance of glial factor-like activity in rat brain primary cultures, Nature, 273 (1978) 308-309.

22 Scott, R.W., Bergman, B.L., Bajpai, A., Hersh, R.T., Rodriguez, H., Jones, B.N., Barreda, C., Watts, S. and Baker, J.B., Protease nexin: properties and a modified purification procedure, J. Biol. Chem., 260 (1985) 7029-7034.

23 Towbin, H., Staehelin, T. and Gordon, J., Electrophoretic transfer of proteins from polyacrylamide gels to nitrocellulose sheets: procedure and some applications, Proc. Natl. Acad. Sci. U.S.A., 76 (1979) 4350-4354.

24 Valinsky, J.E. and Le Douarin, N.M., Production of plasminogen activator by migrating cephalic neural crest cells, EMBO J., 4 (1985) 1403-1406.

25 Wagner, S.L., Lau, A.L. and Cunningham, D.D., Binding of protease nexin-1 to the fibroblast surface alters its target proteinase specificity, J. Biol. Chem., 264 (1989) 611-615.

26 Serine Proteases and Serpins in the Central Nervous System. In B.W. Festoff (Ed.), Plenum, New York, 1990. 